\title{
Virtual Classroom: To Create A Digital Education System in Bangladesh
}

\author{
Faieza Chowdhury ${ }^{1}$ \\ ${ }^{1}$ Southeast Business School, Southeast University, Dhaka 1213, Bangladesh \\ Correspondence: Faieza Chowdhury, Southeast Business School, Southeast University, Dhaka 1213, Bangladesh
}

Received: February 4, 2020

Accepted: March 10, 2020

Online Published: March 12, 2020

doi:10.5430/ijhe.v9n3p129

URL: https://doi.org/10.5430/ijhe.v9n3p129

\begin{abstract}
The use of web-based tools for educational purposes is a rapidly growing trend in Bangladesh. Most of the academic institutions in Bangladesh have decided to develop academic portals where teachers can create online versions of their courses. This paper addresses students' opinions on the use of virtual classroom from their own personal experiences and identifies features of virtual classroom that are vital to create an interactive student-centered learning environment. We try to understand whether the use of virtual classroom can bring improvement in students' learning and performance in the class. The results from binary logistic regression indicate that most of the participants have positive opinions regarding the usage of virtual classroom for learning purposes. As the present Government of Bangladesh (GOB) has urged all higher education institutions (HEIs) to take effective measures in order to implement 'Integrated University Information Management Platform', the findings from this study will help educators and administrators to understand how to construct an interactive student-friendly academic portal that will fulfill all the needs of the customers and to assess whether the features of the existing portals that they are currently using need any further improvements.
\end{abstract}

Keywords: virtual classroom, e-learning, educational technology, student-centered learning, binary-logistic regression, Bangladesh

\section{Introduction}

Unlike USA and Europe, in Bangladesh there is still a tradition of teacher-centered repetitive pedagogy (Andersson, 2008; Pagram \& Pagram, 2006). The 2016-17 Household Income and Expenditure Survey (HIES), for the first time, provided poverty estimates at quarterly intervals and at the district level. Almost 1 in 4 Bangladeshis (24.3 percent of the population) live in poverty, and 12.9 percent of the population lives in extreme poverty (World Bank, 2017). However, the number of people using the internet technology in Bangladesh has increased rapidly over the last decade. As Bangladesh is gradually moving towards the goal of digitalizing the nation, the use of information and communication technology (ICT) to create an active learning environment at higher education institutions (HEIs) is vital.

E-learning is often seen as a tool for supplying teaching materials and not for improving teaching methods by means of interactivity (Jiang \& Ting, 2000). E-learning is better than the traditional mode of instruction as educators and students are not restricted to specific geographical location. According to Collis (1996), e-learning fosters development of group cohesion and a sense of community, encourages discipline in learning and provides quick feedback and support consensus and decision-making.

Virtual classroom is a form of online learning environment (Wang \& Newlin, 2012). Other terminologies used to define the online delivery of instruction are network-based learning, tele-learning, web-based learning and e-learning (WCET, 2004). Virtual classrooms allow podcasting where teachers can download videos and audio files onto a digital media platform via a computer. Students can then watch these files when and where as per their own convenience (Evans, 2008). The use of virtual classroom requires sophisticated end-user equipments and internet access. In Bangladesh it is estimated that access to mobile phones at the household level is almost $90 \%$ in urban areas and $70 \%$ in rural sector (Rahman, 2007). Hence as the mobile phone usage in Bangladesh is rapidly increasing this has upgraded communication of every form. Students can easily access virtual classroom via their mobile phones and check uploaded teaching materials and messages posted by their teachers. Moreover, due to the advancement of ICT in Bangladesh, networks and internet access have been upgraded in the last 10 years.

However, to create an online learning environment at HEIs in Bangladesh it is imperative for academic institutions to strive for a low-cost approach by using the cheapest and widely available aids of technology. While the technology 
that we can currently use in Bangladesh is quite limited but it is possible to create a learner-centered environment with free online-education tools such as Google Classroom and Moodle. Changing from one pedagogical tradition to another is not an easy fleet. Users must construct and arrange technology effectively; merits of the chosen aids must be communicated to all respective parties. Prior to using any new technological tools in the class, a prototype must be developed and tested in real settings. It is also vital for educators and administrators to ensure that the chosen mode of technology fits the current teaching pedagogy.

Although a wide research on virtual classroom have been conducted earlier but not many studies were performed in the context of Bangladesh. Nevertheless, there are some organizations which are trying to research and develop the virtual education system in Bangladesh such as a publishing company of technological magazines and news (www.comjagat.com) and Jaago School which is an online school. Internet Classroom Assistant (ICA) is an online tool for web based managing scheduling, conferencing and sharing resources to different kinds of learning environment. In Bangladesh the first online classroom was 'CJ online classroom' developed by a large IT Magazine company called 'Computer Jagat'.

The significance of this research lies in the fact that it contributes to the body of knowledge in a way that many stakeholders mainly; students, universities and system administrators will be benefited from the findings of this study. In this article we point out which characteristics and features of virtual classroom are more useful to the students so that university authorities and system administrators will gain awareness about the matter and take appropriate actions while developing their own integrated university information management platforms.

This paper addresses the following questions: (1) What are the key features of a virtual classroom to create a student-centered learning environment? (2) What is the perceived usefulness of a virtual classroom on students' learning at HEIs in Bangladesh? (3) What are the various benefits of using a virtual classroom for the students, teachers and university management? (4) In what ways can we bring further improvements in the development and usage of virtual classroom in Bangladesh?

The remainder of this article is divided into six sections. Section 2 summarizes the reviewed literature, Section 3 highlights the main features and benefits of virtual classroom, Section 4 explains the research methodology, Section 5 reveals the findings of the study and Section 6 provides the conclusion by giving appropriate recommendation.

\section{Literature Review}

Technology such as the virtual classroom is becoming increasing popular in today's modern world (Flatley, 2007; Gilmore \& Warren, 2007; Arbaugh, 2000). A virtual classroom is an online learning environment (Wang \& Newline, 2012). Virtual classroom program was initially launched by AT \& T in the fall of 1996. During the period of 1996 through 2000, more than 19000 students from different countries around the world used virtual classroom to collaborate and learn via the internet (Hiltz, 1994). Although virtual education environment proceeded in a one way structure during the 1990s, it has been observed that virtual education have presented bidirectional interaction and three dimensional study environments by 2000. Arbaugh (2000) reveal that perceived usefulness and ease of technology influences one's beliefs and attitudes towards the technology. According to Khan (2000), well-designed course interfaces can anticipate learners' needs and satisfy their natural curiosity to explore the unknown. Khan and Ivy (2017) found in their study that digital environment lead to positive attitude because students felt there was no pressure of accuracy. Keeler (2014), suggest that virtual classroom such as 'Google Classroom' encourages collaboration between the students. Virtual classroom can also provide students with quick feedback in the form of 'just-in-time' clarification and information. Moreover, in a virtual classroom, students can easily interact with their peers in real time which is often not possible in other forms of communication (Pan \& Sullivan, 2005). Tsui and Ki (1996) point out that online classroom allow students to enhance their interaction with classmates over the course of their study as they become more comfortable using different technologies. The interactivity in virtual classroom creates a more active learning environment and instructors can post various class discussion topics using an electronic whiteboard in a virtual classroom.

\section{Features and Benefits of Virtual Classroom}

\subsection{Main Features of Virtual Classroom}

Today educators can select from different types of virtual classrooms which are freely available online for the users such as Google Classroom, Moodle etc. However, educators must ensure that the virtual classroom that they have selected as aid to teaching has all the necessary features to support student activity and learning. 
It is important to create a virtual classroom environment with robust features that include audio, video and file sharing tool, online grading and group chatting. Some virtual classrooms have features to promote interactions among the students such as easy-to-use interactive annotations and charting tools.

Moreover, an integrated digital academic platform can be utilized for various purposes including learning, communication, administration and teacher support. In this section we have listed down some of the key features of a virtual classroom which can assist course instructors to create an interactive learning environment.

\subsubsection{Teaching Purpose}

- Uploading Files: Virtual classroom can be used to upload word/pdf files, audios and videos. The system provides a dashboard available to the users where they can view the files uploaded by the course instructor and access these files from any electronic devices including computers and mobiles. Teachers can also upload recorded lectures for those students who have missed the classes due to some unavoidable circumstances such as accident or sickness.

- Assignment Submission and Grading: For the purpose of keeping the students active in the class, teachers can upload home task and/or assignments in the virtual classroom. Students can easily access the files via the online platform and interact with their peers while trying to complete their home task. Teachers can view how many students have submitted the task in an online submission desk and grade the students quickly in the online platform.

- Self-Assessment Exams: After the instructor has completed a chapter he/she can conduct an online examination to evaluate the students' understanding of the concepts discussed in the class. For this purpose the teacher can create a database of questions from each chapter or lessons covered within the class so that the system will automatically retrieve from the database and arrange the questions into different sets. These online examinations can be attempted from home and students will automatically get the scores after they complete the exams. The exams may be graded or non-graded depending on the instructor's preference of evaluating his/her students.

- Discussion Threads/Group Chats: The teachers can post a message or upload video files seeking to obtain response from the students in an online interaction feed. The opinions of each student are displayed in a feedback box and each student can see the response of their peers within the interaction feed section and engage in online group discussions. Teachers can also give points to students for online class participation.

- Messaging Box: There is a message box where teachers and students can post messages which can be viewed by all the students in the class. The message sharing option can also be restricted to few numbers of students as per the preference of the course instructor. The messages can be arranged either by date or posting order. Hence, virtual classrooms can be used to facilitate communication among the students and between teacher and students.

- Online Grading and Assessment: Teachers can use virtual classrooms to conduct online exams. Different sets of questions from different chapters or lessons can be stored in the database. After completion of a lesson, students can sit for online exams which are automatically graded by the system. Students can also get immediate feedback from the course instructor regarding their exams. The online system can also point out in which specific areas of the lesson/chapter they are weak hence require further improvement. Students can get immediate feedback on the accuracy of their answers and conduct discussions on incorrect answers with their peers in a live group chatting session. The online examination system is also beneficial for the course teachers as they can identify the strengths and weaknesses of their class students. For instance, if most of the students in the class got poor grades in a particular lesson/chapter then the teacher may try to understand the reasoning behind it and if necessary repeat the chapter/lesson in the class.

\subsubsection{Administrative Purpose}

Academic portals can be used for various administrative purposes. Instructors can use this to take online students' attendance in the class. It can also allow students to monitor which students are irregular and inactive in the class so that corrective measures can be taken accordingly. Academic portals enable teachers to grade and publish students' results in online system. Hence, teachers can publish results which students can access easily from anywhere in the world. Moreover, teachers can evaluate students' performance in an online platform and give feedback to each student on how to improve performance in the future. Virtual classroom also allow teachers to maintain a database of all students in various classes so that teachers can continuously monitor students' performance and grade them accordingly. Such statistics also allow the teachers to formulate improvement plans for the students especially when some of the students in the class are retaking the courses. 


\subsection{Benefits of Virtual Classroom}

Due to the advancement of ICT over the last decade in Bangladesh, teachers are now forced to adopt technology in teaching. According to Martin and Parker (2014), many faculties today are using synchronous virtual classrooms that allow them to interact with students in real time. A widely used example of a virtual classroom is the Google Classroom which is a learning management system launched by Google in May 2014.

A teacher can open specific classrooms composing of sections and topics. Creating a virtual classroom is relatively easy as the user only needs an active email account to use the system. Users also need to provide some essential data to $\log$ into the system such as username, password, name of class/course, section etc. Generally it will take only 2 to 3 minutes to create an account in a virtual classroom. For each virtual class created by the teacher, a unique class code is automatically generated by the system. Once the student gets access to the class code then they can easily $\log$ into the system and use all the features.

\section{A virtual classroom provides a set of features which can help educators in various ways as listed below:}

- Saves Time: It can enable educators to keep their teaching resources and materials in an organized way thus saving valuable work time. Hence a virtual classroom is an ideal tool to enhance teachers' workflow and productivity.

- Widely Accepted: Virtual classrooms such as Google Classroom are widely endorsed within the education community.

- Costless: Most of the education management systems are free and readily available online for all the users with little to no cost.

- Eco-Friendly: The use of virtual classroom fosters the creation of an eco-friendly environment as teachers can collect assignment and materials online thus eliminating the need to use papers.

- Accessibility: Virtual classroom provides learner autonomy as students can use the tools available to them from any place, at any time and in any number of times. Most of the learning applications are easily usable and accessible from any portable electronic devices such as laptops and mobile phones. Virtual classroom is also beneficial to those students who come from remote areas and may find difficult at attend lectures regularly in a formal classroom settings.

- Wide Storage: In most of the education management systems there is a wide unlimited storage facility which allows users to store their work in paperless form for a long period of time.

- Online Tracking System: Faculties can use the online tracking mechanism to identify which students in the class are struggling and in need of further assistance. By using the online grading tool it is possible to assess students' work and submit the grades automatically within the system. Hence virtual classroom also simplifies the grading system for the course instructor.

- User Friendly: In most of the cases, the virtual classrooms are user friendly hence both teachers and students can easily use the system without any formal training however, if necessary video tutorials can be provided to the users.

- Flipped Classroom: Virtual classroom can also enable teachers to use the flipped instructional mode of teaching.

\section{Methodology}

In this study we have conducted both quantitative and qualitative research. We want to investigate the opinions of 120 undergraduate students regarding the usage of virtual classroom on students' learning at a higher academic institution in Bangladesh. A structured questionnaire was designed and 120 undergraduate students at a reputed private university in Bangladesh were surveyed. All the selected participants have attended at least one course of study in which the course instructor utilized the virtual classroom as an aid to teaching and learning. In addition, personal interviews were conducted to determine students' opinion of virtual classroom usage in the class. All feedback from the participants were evaluated, classified and discussed.

This section is divided into five sub-sections: 1. target group, 2. sampling technique, 3. data collection, 4. data analysis and 5. regression model. 


\subsection{Target Group}

The survey was conducted on 120 undergraduate students enrolled in BBA program at one of the private universities in Bangladesh.

\subsection{Sampling Technique}

The selection of the participants for the study was based on simple random sampling (SRS) technique. From a total population of 400 undergraduate BBA students, 120 students were selected as the final sample size using SRS technique. The sample size was determined using the online survey calculator considering $5 \%$ margin of error at $95 \%$ confidence level.

\subsection{Data Collection}

A questionnaire was administered to collect primary data on students' learning improvement due to the usage of virtual classroom by the course instructor. The opinion of 120 undergraduate students on the effectiveness of virtual classroom and awareness of course instructors on using modern technology in teaching was further analyzed. Moreover, in qualitative study we have conducted interviews with 30 undergraduate students on the basis of purposive sampling.

\subsection{Data Analysis}

This study took the efforts to explore the different types of benefits that students gain due to the usage of virtual classroom as part of their learning process in the class. Firstly, we followed the quantitative data analysis procedure to collect primary data using a structured questionnaire. The findings from quantitative analysis are divided into two parts. In part A [Table 1], descriptive analysis (e.g. frequency and percentage) was used to collect information on nine close ended questions. The answers were analyzed in terms of frequency occurrences which were later converted to percentages. This procedure required us to follow the three steps: Step 1, figuring out the absolute frequency by counting the total number of occurrences. Step 2, dividing the absolute frequency by the total cluster of responses to get the relative frequency and Step 3, by multiplying the relative frequencies with 100 to calculate the percentages. In part B of the quantitative research [Table 2], we have used the binary logistic regression to assess the opinions of the students regarding the usage of virtual classroom on learning. Students were asked to provide their opinions on nine closed-ended questions. Five-point Likert scale was used to assess each of the statements in the questionnaire with five options which were strongly agree (SA), agree (A), neutral (N), disagree (DA) and strongly disagree (SDA).

\subsection{Regression Model}

One of the prime objectives of the study was to measure whether the usage of virtual classroom does bring any improvement on students' learning. The binary logistic regression is an appropriate technique to use when the dependent variable is dichotomous (Mahmud et al., 2014). In this study, binary logistic regression model was applied because the dependent variable 'improvement in students' learning' can have two outcomes: "usage of virtual classroom does bring improvement in students' learning" was coded as 1 and "usage of virtual classroom does not bring improvement in students' learning" was coded as 0 .

The model can be specified as:

$$
\mathrm{Pi} /[1-\mathrm{Pi}]=\alpha+\beta_{1} \mathbf{X}_{1}+\beta_{2} \mathbf{X}_{2}+\beta_{3} X_{3}+\beta_{4} X_{4}+\beta_{5} X_{5}+\beta_{6} X_{6}+\beta_{7} X_{7}+\beta_{8} X_{8}+\beta_{9} X_{9}+\mu
$$

where:

$\mathrm{P}_{\mathrm{i}}=$ probability that students learning will improve due to the usage of virtual classroom

$\left[1-\mathrm{P}_{\mathrm{i}}\right]=$ probability that students learning will not improve due to the usage of virtual classroom

$\mathrm{X}_{1}=$ enhanced accessibility to teaching materials;

$\mathrm{X}_{2}=$ regular class updates on lectures and exams;

$\mathrm{X}_{3}=$ easy contact with peers and teachers;

$\mathrm{X}_{4}=$ enhanced communication;

$\mathrm{X}_{5}=$ greater sharing of ideas;

$\mathrm{X}_{6}=$ availability of online lectures;

$\mathrm{X}_{7}=$ availability of online exams;

$\mathrm{X}_{8}=$ online assignment and grading system; 
$\mathrm{X}_{9}=$ easy videos, audios and presentation sharing;

$\alpha=$ is the constant for the equation;

$\beta=$ coefficient of the independent variable; and

$\mu=$ is the error term for the equation.

\section{Findings and Discussion}

\subsection{Findings from Quantitative Study}

In Table 1, we analyzed the responses of participants based on nine closed-ended questions constructed on a 5-point Likert scale in order to measure the extent to which virtual classroom can influence students' learning. In the first statement, 120 students were asked about the accessibility feature of a virtual classroom. 85 students responded that they strongly agree that a virtual classroom enable them to access the learning materials easily and quickly while 2 participants disagreed to this statement. In the second item, $80 \%$ of the respondents strongly agree that virtual classroom helps to get regular updates about the class whereas less than $3 \%$ of the respondents disagreed to this statement. In terms of easy interaction with course teachers and peers, 53\% students strongly agreed, 37\% agreed and less than 5\% respondents disagreed. Students were asked whether use of virtual classroom enhance their learning due to the use of various teaching aids such as audio and video. $48 \%$ of the respondents strongly agreed, $37 \%$ agreed and only $3 \%$ students disagreed. In statement six, students were asked whether a virtual classroom enable them to share ideas easily with their peers. $23 \%$ responded with a strong positive note, $64 \%$ agreed while only $3 \%$ of the students stated that this is not always the case. In statement seven, students were asked whether virtual classroom is useful for delivering online lectures. 67 out of 120 students strongly agreed, 41 agreed and only 3 students disagreed. In statement eight, we asked the students whether virtual classroom is useful for conducting online exams. Here $46 \%$ strongly agreed, $38 \%$ agreed and only $3 \%$ disagreed. Finally, in statement nine we asked the students whether virtual classroom is useful for online assignment submission and grading. As per the responses, 52\% strongly agreed, 39\% agreed and only $2 \%$ disagreed to this statement.

Table 1. Analysis of Closed-response Items

\begin{tabular}{|c|c|c|c|c|c|c|c|c|c|c|}
\hline \multirow[b]{2}{*}{ Statements } & \multicolumn{2}{|c|}{$\begin{array}{l}\text { Strongly } \\
\text { Agree }\end{array}$} & \multicolumn{2}{|c|}{ Agree } & \multicolumn{2}{|c|}{ Neutral } & \multicolumn{2}{|c|}{ Disagree } & \multicolumn{2}{|c|}{$\begin{array}{l}\text { Strongly } \\
\text { Disagree }\end{array}$} \\
\hline & Res & $\%$ & Res & $\%$ & Res & $\%$ & Res & $\%$ & Res & $\%$ \\
\hline $\begin{array}{c}\text { Virtual classroom helps you to } \\
\text { access all materials easily and } \\
\text { quickly. }\end{array}$ & 85 & 71 & 26 & 22 & 7 & 6 & 2 & 1 & 0 & 0 \\
\hline $\begin{array}{l}\text { Virtual classroom helps you to } \\
\text { get regular updates about the } \\
\text { class. }\end{array}$ & 96 & 80 & 19 & 16 & 1 & 0.7 & 3 & 2.5 & 1 & 0.8 \\
\hline $\begin{array}{l}\text { Virtual classroom helps you to } \\
\text { easily contact the course teacher. }\end{array}$ & 64 & 53 & 44 & 37 & 6 & 5 & 4 & 3.3 & 2 & 1.7 \\
\hline $\begin{array}{l}\text { Virtual classroom helps you to } \\
\text { learn through various modes such } \\
\text { as videos, audios etc. }\end{array}$ & 58 & 48 & 44 & 37 & 14 & 12 & 4 & 3 & 0 & 0 \\
\hline $\begin{array}{l}\text { Virtual classroom helps you to } \\
\text { easily share ideas with peers. }\end{array}$ & 23 & 19 & 64 & 53 & 30 & 25 & 2 & 2 & 1 & 1 \\
\hline $\begin{array}{l}\text { Virtual classroom enhances } \\
\text { communication among students } \\
\text { in the class. }\end{array}$ & 55 & 46 & 48 & 40 & 12 & 10 & 5 & 4 & 0 & 0 \\
\hline $\begin{array}{l}\text { Virtual classroom is useful for } \\
\text { delivering online lectures. }\end{array}$ & 67 & 56 & 41 & 34 & 9 & 8 & 2 & 1 & 1 & 1 \\
\hline $\begin{array}{l}\text { Virtual classroom is useful for } \\
\text { conducting online exams. }\end{array}$ & 55 & 46 & 46 & 38 & 16 & 13 & 3 & 3 & 0 & 0 \\
\hline $\begin{array}{l}\text { Virtual classroom is useful for } \\
\text { online assignment submission } \\
\text { and grading. }\end{array}$ & 62 & 52 & 47 & 39 & 8 & 7 & 1 & 1 & 1 & 1 \\
\hline
\end{tabular}


In Table 2, we have shown the results from the binary logistic regression. The dependent variable is dichotomous and indicates the probability that students learning will or will not enhance due to the usage of virtual classroom. This was assessed using nine key indicators: greater accessibility to class materials $\left(\mathrm{X}_{1}\right)$, regular class updates $\left(\mathrm{X}_{2}\right)$, easy contact with course teacher and peers $\left(\mathrm{X}_{3}\right)$, enhanced communication $\left(\mathrm{X}_{4}\right)$, greater sharing of ideas $\left(\mathrm{X}_{5}\right)$, online lectures $\left(\mathrm{X}_{6}\right)$, online exams $\left(\mathrm{X}_{7}\right)$, online assignment and grading $\left(\mathrm{X}_{8}\right)$ videos, audios and presentation tools $\left(\mathrm{X}_{9}\right)$. It is expected that these nine features of virtual classroom will improve students' learning in the class. The results of the binary logistic regression indicate that easy contact with course teacher and online lecture; these two variables are positively and significantly related to the dependent variable "student learning". Hence students' learning will enhance if students are provided the opportunity to easily contact their course teacher and get instant feedback. Moreover, it also represents that students' learning will improve if they are provided online lectures by the course instructor. Other four independent variables such as idea sharing, online exams, online assignment and online grading are also positively related to the dependent variable though the results are not significant. Two of the independent variables mainly, class updates and enhanced communication with peers is negatively related to the dependent variable. This indicates that these two features of the virtual classroom do not contribute much to the enhancement of students' learning. We have calculated the probability of the coefficients using the odd ratios from the binary logistic regression. In Table 2, the probability that greater access to teaching materials will enhance students' learning is $82 \%$. Moreover, the probability of enhancement in students' learning due to greater contact with course teacher and online exam features are $89 \%$ and $88 \%$, respectively. Overall, the findings from the binary logistic model indicate that most of the features of virtual classroom do have a positive impact on students' learning.

Table 2. Results of Binary Logistic Regression

\begin{tabular}{cccc}
\hline Variables & Coefficient & $\begin{array}{c}\text { Level of } \\
\text { Significance }\end{array}$ & $\begin{array}{c}\text { Odd } \\
\text { Ratio }\end{array}$ \\
\hline Enhanced accessibility & 1.518 & 0.267 & 4.566 \\
Regular class updates & -1.829 & 0.175 & 0.16 \\
Easy contact with teachers & 2.084 & 0.045 & 8.043 \\
Other modes such as video, audio etc & 0.264 & 0.821 & 1.302 \\
Greater sharing of ideas & 0.821 & 0.584 & 2.273 \\
Enhanced communication with peers & -0.241 & 0.859 & 0.786 \\
Online lectures & 1.998 & 0.025 & 7.381 \\
Online exams & 1.611 & 0.246 & 5.006 \\
Online submission and grading & -1.512 & 0.346 & 0.221 \\
\hline & Pseudo R ${ }^{2}: 0.6137$ & \\
\hline
\end{tabular}

\subsection{Findings from Qualitative Study}

The key objective of this paper is to analyze students' opinion regarding the usage of virtual classroom as a tool for learning. Features of the virtual classroom that students find more beneficial as well as suggestions on further improvements will be explored. An interview was conducted where 30 undergraduate students were asked 10 open-ended questions to express their views on the usage of virtual classroom. All feedback gained from the participants were based on their own personal experience who got the chance to use virtual classroom in at least one previous course of study.

Some examples of data obtained in the analysis of the responses are briefly listed below:

"I think virtual classroom is very good for us because it allows us to get the study materials easily"

"Virtual classroom is fun because we can watch videos and presentation"

"In virtual classroom I gave an online quiz which was automatically graded by the system. This helped me to improve my performance in written exam"

"I was out of the country but by using virtual classroom I have submitted my assignment to my teacher through online without any delay" 
When similar responses were obtained from different respondents, their opinions were considered as prominent. The three main findings from the qualitative study were as follows: [1] Virtual classroom is positively viewed as an effective teaching aid by most of the respondents. [2] Most of the students liked the file sharing option of virtual classroom [3] Students also find the accessibility feature desirable as they can enter the virtual classroom any time from any place.

\section{Conclusion}

As Bangladesh is slowly moving towards achieving its dream of becoming a digitalized nation, the education sector needs to be revamped. Use of technological aids in teaching such as virtual classroom enables teachers to create a collaborative student-centered learning environment. However, this will require considerable effort from the teachers as they have to prepare lecture notes, question banks, learning lessons etc to upload these materials in an online platform. Virtual classroom requires different pedagogical methods than the repetitive and traditional 'chalk and talk' teaching approach. Unfortunately the local educational culture in Bangladesh, like many other developing countries is focused on repetition and memorization. To bring a change in this norm is a huge challenge. While the process of change in pedagogy may be faster for developed countries due to their open-minded cultural aspect and technological advancements, one cannot expect the educational culture in a developing country such as Bangladesh to change overnight.

Nonetheless, to become a next-generation university, it is vital for all higher education institutions (HEIs) in Bangladesh to make a significant transition towards digital education. However, as discussed earlier, changing from one pedagogical tradition to another is not an easy fleet to achieve and requires education institutions to overcome certain impediments. First of all, there is a need for appropriate teachers' training to create awareness about the latest teaching developments and technologies practiced around the world. Teachers should be encouraged to adopt new pedagogies and shift from teacher-centered to student-centered teaching and learning approaches. Academic institutions should provide trainings to teachers on how to use various technological aids to create an active learning environment. Teachers should be encouraged to redesign their courses and incorporate virtual classroom in all classes to create a more interactive and collaborative learning environment. It is also vital to ensure that any chosen educational online platform is compatible with the existing curriculum and the institutional context. Moreover, an important aspect of using virtual classroom for teaching purposes is that it must be economically feasible, which means users can get the facilities at little to no cost. As the development of a virtual classroom does not require major investments of money, hence it is a low cost scheme and affordable approach to foster interactive learning at HEIs in Bangladesh. It allows a holistic student learning experience by merging both physical and online modes of teaching.

Currently most of the literatures on virtual classroom are descriptive and the main emphasis is on practice. (Halper, Kelly \& Chuang, 2007; Gilmore \& Warren, 2007; Grosjean \& Sork, 2007; Mckinnie, 2008).The purpose of this study is to examine the students' perception of the virtual classroom in an instructional course and identify which features and characteristics of virtual classroom they find more useful more learning purposes. The results from this study indicate that most of the features of virtual classroom were positively received by the students who particularly mentioned easy access to the course teacher and online lecture features as the key advantages of a virtual classroom. According to Mc Isaac \& Gunawardena (1996), one major advantage of virtual classroom is that it provides a two-way interaction between students and instructors. Students can easily contact their course instructors via online portal and get quick feedback on any queries raised by students related to the course content. This means that virtual classroom allow students to gain 'just-in-time feedback' from the course teacher. Another unique benefit of virtual classroom is that it allows the students to learn at their own pace as students can stop, rewind, replay and fast forward recorded video lectures. Students who fail to attend formal classes due to illness or disabilities can watch the recorded lectures in virtual classroom any time suitable to them. Virtual classroom allow students to repeat the materials until they gain mastery over it. Moreover, most of the respondents of this study also stated that virtual classroom allow them to share learning resources, communicate and engage in group discussions and watch various educational videos. The findings from this study corroborates the previous works of researchers who proved that virtual classroom can play a significant role in enhancing students' learning and achievements such as Miltiadou \& Savenye, (2003); Riel \& Harasim, (1994); Verduin \& Clark, (1991); and Vrasidas \& McIsaac, (1999). Although like any other teaching aids, virtual classroom do have some limitations but it is an instrumental tool to foster interactive students' learning over a medium which is affordable and easily accessible to all.

However like any other research, this study has some limitations. Firstly, the study was conducted on respondents from a single academic institution and the sample size was restricted to 120 undergraduate students. Hence an 
expansion of this study can examine the use of virtual classroom across a wider variety of population, academic programs and disciplines. Secondly, this is a cross-sectional study hence further research can be conducted using longitudinal data to assess the perception of students regarding the usage of virtual classroom for learning over a period of time.

\section{References}

Andersson, A. (2008). Letters from the field: e-Learning students change of learning behaviour in Sri Lanka and Bangladesh. Paper presented at the 7th European Conference on e-Learning (ECEL), Agia Napa, Cyprus.

Arbaugh, J. (2000). Virtual classroom characteristics and student satisfaction with internet based MBA courses. Journal of Management Education, 24(1), 32-54. https://doi.org/10.1177/105256290002400104

Collis, B. (1996). Tele-learning in a digital world: The future of distance learning. London. International Thompson Computer Press.

Evans, C. (2008). The effectiveness of m-learning in the form of podcast revision lectures in higher education. Computers \& Education, 50(2), 491-498 https://doi.org/10.1016/j.compedu.2007.09.016

Flatley, M. E. (2007). Teaching the Virtual Presentation. Business Communication Quarterly, 70(3), 301- 305. https://doi.org/10.1177/1080569907305305

Gilmore, S. \& Warren, S. (2007). Themed article: Emotion online: Experiences of Teaching in a Virtual Learning Environment. Human Relations, 60(4), 581-608. https://doi.org/10.1177/0018726707078351

Grosjean, G. \& Sork, T. J. (2007). Going online: Uploading learning to the Virtual Classroom. New Directions for Adult and Continuing Education, 113, 13-24. https://doi.org/10.1002/ace.243

Halper, S., Kelly, K. \& Chuang, W. H. (2007). A Reflection on Course stream system: A Virtual Classroom streaming system designed for large classes. Tech Trends, 51(2), 24-27. https://doi.org/10.1007/s11528-007-0022-Z

Hartnett, M., St. George, A. \& Dron, J. (2011). Examining motivation in online distance learning environments: Complex, multifaceted, and situation-dependent. The International Review of Research in Open and Distance Learning, 12, 20-38. https://doi.org/10.19173/irrodl.v12i6.1030

Hiltz, S. R. (1994). The virtual classroom: Learning without limits via computer networks. Intellect Books.

Jiang, M. \& Ting, E. (2000). A study of factors influencing students' perceived learning in a web-based course environment. International Journal of Educational Telecommunications, 6(4), 317-338.

Keeler, A. (2014). 15 More things you can do with Google Classroom.

Khan, B. H. (2000). Discussion of Resources and Attributes of the web for the Creation of meaningful Learning Environments. Cyber Pyschology \& Behavior, 3(1), 17-23. https://doi.org/10.1089/109493100316193

Khan, R. \& Ivy, T. I. (2017). Exploring the Factors Affecting Bangladeshi Tertiary Level Students' Attitude towards L2 Writing, In Coombe, C. \& Khan, R. (Eds): BELTA Bangladesh. Best Practice in ELT Voices from the Classroom (pp. 308). (Reprinted from online by TESOL Arabia, Dubai, UAE, Dubai: TESOL Arabia Publications).

Martin, F. \& Parker, M. A. (2014). Use of Synchronous Virtual Classrooms: Why, Who and How? MERLOT Journal of Online Learning and Teaching, 10(2), 192-210.

McIsaac, M. S. \& Gunawardena C. N. (1996). Distance Education. In D. H. Jonassen (Ed.), Handbook o research for educational communications and technology: a project of the Association for Educational Communications and Technology (pp. 403-437). New York: Simon \& Schuster Macmillan.

McKinnie, R. (2008). Best practices for delivering virtual classroom training. White Paper, Adobe Systems Incorporated.

Miltiadou M. \& Savenye, W. C. (2003). Applying Social Cognitive Constructs of Motivation to Enhance Student Success in Online Distance Education. Educational Technology Review, 11(1).

Pagram, P. \& Pagram, J. (2006). Issues in e-learning: A Thai case study. The Electronic Journal of Information Systems in Developing Countries, 26(6), 1-8.

Pan, C. C. \& Sullivan, M. (2005). Promoting synchronous interaction in an eLearning environment. Technical Horizons in Education Journal, 33(2), 27-30.

Rahman, M.Z. (2007). Bridging the gap between rural students and the university: Alternative vision of student 
support in Bangladesh (Master Thesis). Faculty of Education, Deakin University, Geelong, Australia.

Riel, M. \& Harasim, L. (1994). Research Perspectives on Network Learning. Machine Mediated Learning, 4(2- 3), 91-113.

Tsui, A. B. M. \& Ki, W. W. (1996). An Analysis of Conference Interactions on Telenex - A Computer Network for ESL Teachers. Educational Technology Research and Development, 44(4), 23-44. https://doi.org/10.1007/BF02299819

Verduin, J. R. J. \& Clark, T. A. (1991). Distance Education: The Foundations of Effective Practice. San Francisco: Jossey-Bass.

Vrasidas, C. \& McIsaac, M. S. (1999). Factors Influencing Interaction in an Online Course. The American Journal of Distance Education, 13(3), 22-35. https://doi.org/10.1080/08923649909527033

Wang, A. Y. \& Newlin, M. H. (2012). Online Lectures: Benefits for the Virtual Classroom. T.H.E. Journal.

WCET: Western Cooperative for Educational Telecommunications (2004). Distance education: A consumer's guide.

World Bank, IBRD, IDA. (2017). Bangladesh Continues to Reduce Poverty but at Slower Pace. Retrieved 12, May 2019 